\title{
A CALL FOR HOLISTIC APPROACH TO DEFENCE TRANSPARENCY IN SOUTH EAST EUROPE
}

\author{
Todor Tagarev, ed., Transparency in Defence Policy, Military Budgeting and \\ Procurement (Sofia, Geneva Centre for the Democratic Control of Armed \\ Forces and George C. Marshall Association-Bulgaria, 2002). \\ ISBN 954-91092-1-6.
}

$\mathrm{T}$ his book is a result of the Sofia-2001 workshop organized by the Geneva Centre for the Democratic Control of Armed Forces (DCAF) and the Ministry of Defence of the Republic of Bulgaria in the framework of the Working Table III of the Stability Pact for South Eastern Europe (SEE). It provides a wide basis for understanding the concepts of transparency and accountability in defence planning, budgeting and procurement. Such understanding is crucial, especially for the South East European region - region with a 'rich' history of mutual suspicion, even antagonism.

The theses of the contributors support the idea that via both transparency and accountability, an open discussion of security planning is generated and maintained. These concepts strongly relate to the important issues of 'good practice' and 'good governance,' removing them from realm of party and clique or from within the bureaucratic corridors. Increasing transparency, defence establishments in SEE have the chance of a successful transformation based on a less rigidly planned, less stasisoriented process in response to a country's broader security environment. In light of such conceptual shift, security has been seen not as the product of some 'secret capacities,' but as a dynamic balance between threats and capabilities. As Daniel Nelson concludes in his article "Beyond Defence Planning," "From planning a defence against others - from within the confines of a comfortable clubhouse into which few others will be admitted - we need to move towards the notion of security with others. Not a clubhouse good but a public good, security for each member is at best partial unless it is holistic.'

The contributing authors gather around the insight that the SEE defence planners have to be ready for a significant change in their thinking. Care must be taken that every state's security is no longer the domain of an intra-party elite, who once could 
guard their control of the opaque resource allocation process for defence. To complete the above mention 'statement,' the book proclaims that the efforts should be taken by the South East European states to increase the effectiveness of democratic control of their armed forces, to contribute to confidence-building among their people and the improvement of regional stability. Encouraging the efficient management of defence resources is also a desirable outcome.

Within the contributions, it is acknowledged that:

- transparency is a complex concept, with both domestic and international aspects; and

- at the heart of democratic decision-making lies the notion of accountability: governments are accountable, through the legislature, to 'the people' - this is an executive obligation; and legislatures are expected to hold governments to account, for both their actions and their expenditures - this is the elected representatives' duty.

By understanding the essence of the concepts for 'transparency' and 'accountability,' the SEE countries will strive to implement modern principles of democratic governance. In this significant endeavour they will encounter controversial issues, gaps and unexpected results that will then need to be corrected. The most significant challenges seem to appear in building transparency in defence policy, military budgeting and procurement, because those functions are considered to be the backbone of the defence establishment.

In the debate on transparency in SEE, the book "Transparency in Defence Policy, Military Budgeting and Procurement" is a real milestone "marking the transition from transparency requirements of international agreements,' aimed at preventing negative developments, towards 'transparency in terms of good practices in governmental accountability and good neighbourly relations.' The book is a thought-provoking forum for exchange of views of eminent experts in security and defence. The contributing articles will help the reader to identify policy options and the areas of defence building that need further enhancement of transparency. 